\title{
Effect of Maximum Power Point Tracking in Photovoltaic Systems and Its Improving and Its Application of Wireless Energy Transmission
}

\author{
Mehmet Ali Özçelik and Ahmet Serdar Yılmaz
}

\begin{abstract}
Despite the advantages of photovoltaic (PV) modules such as noiseless operation, being fuel-free and non-polluting, the most important factors hindering their wide use are high investment costs and low energy conversion efficiencies. By reason of that, studies involving efficiency improvement of the systems fed by PV energy is deemed important. In recent years, studies about PVs have focused on minimize the costs and maximize the conversion efficiency. In order to maximize the efficiency of PV energy conversion systems, solar panels and arrays should be operated at maximum power points (MPP). At MPP, solar arrays generate the electric energy at maximum efficiency and minimum losses. Solar cells have variable current and voltage characteristics and MPP depends on solar irradiations and ambient temperature. So a maximum power tracking control should be made rapidly in different temperature and solar radiation conditions. In this study; solar cell was obtained by using equivalent circuit of solar cell with Matlab / Simulink and by using this structure , a PV generator was designed which is not only used with boost dc / dc convertor but also used with MPPT (maximum power point tracking) unit. Besides due to its easy implementation, P\&O (Perturb-Observe) which is the most common algorithm in PV systems is originally modified for oscillation problem and chosen the design of the MPPT. Finally, wireless energy transmission was applied in conventional and using MPPT PV system on experimental setup for comparing.
\end{abstract}

Index Terms-DC / DC converter, MPPT, P\&O algorithm, PV panel, wireless energy transmission.

\section{INTRODUCTION}

As the sun light hits on PV cells, photo-voltage and photo-current acts like a forward diode on a large surface. The current expression emerging as a result of the sunlight hitting on the cell is given in eq. 1 .

$$
I=I_{P H}-I_{S} \cdot\left\{\exp \left[\frac{q}{A \cdot k \cdot T}\left(V+I \cdot R_{L}\right)\right]-1\right\}-\frac{\left(V+I \cdot R_{S}\right)}{R_{S H}}
$$

In this expression, photo-current, saturation current, load resistance, series equivalent circuit resistance, terminal voltage and load current are denoted by $I_{P H}, I_{S}, R_{L}, R s, R_{S H}, V$ and $I$, respectively.

The equivalent circuit diagram for a solar cell is shown in Fig. 1.

Manuscript received July 14, 2014; revised October 18, 2014.

Mehmet Ali Özçelik is with the Electric and Energy Department, Gaziantep University, Gaziantep, 27310 Turkey (e-mail: ozcelik@gantep.edu.tr).

Ahmet Serdar Y1lmaz is with the Electrical and Electronics Engineering Department, Sutcu Imam University, Kahramanmaras, Turkey (e-mail asyilmaz@ksu.edu.tr).

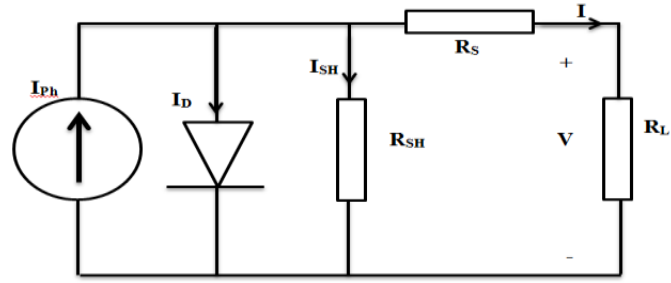

Fig. 1. Equivalent circuit diagram for solar cells.

PV panels, which are created through series or parallel connected solar cells, electrically comprise of a current source, series and parallel resistances and parallel diodes [1]. The relation between the voltage of solar battery cells and current switched on the load exposes $I-V$ and $P-V$ characteristics of the cell. These two characteristics give important clues regarding which conditions are required in order for the power obtained from the panel to reach its maximum level. Obtaining maximum power and reaching highest efficiency level in these panels is an importance research topic [2], [3]. Solar panels act like a current source while, from a certain point onward, they act like a voltage source. Current value that can be obtained from a solar panel is fixed even in case of a short circuit. This value is given along with the plate value of the panel. It is necessary to obtain maximum power from PV panels in any radiation condition [4], [5]. MPP for PV systems varies depending on atmospheric conditions, which are ambient temperature and radiation amount. In general, PV solar panels reach their MPP at around $25^{\circ} \mathrm{C}$. Radiation amount is defined as the sunlight power per unit area [6]-[8]. The effects of radiation on $\mathrm{I}-\mathrm{V}$ and $\mathrm{P}-\mathrm{V}$ characteristics are shown in Fig. 2. This can be shown from following figures, solar radiation increased to the current and power which from solar panels.
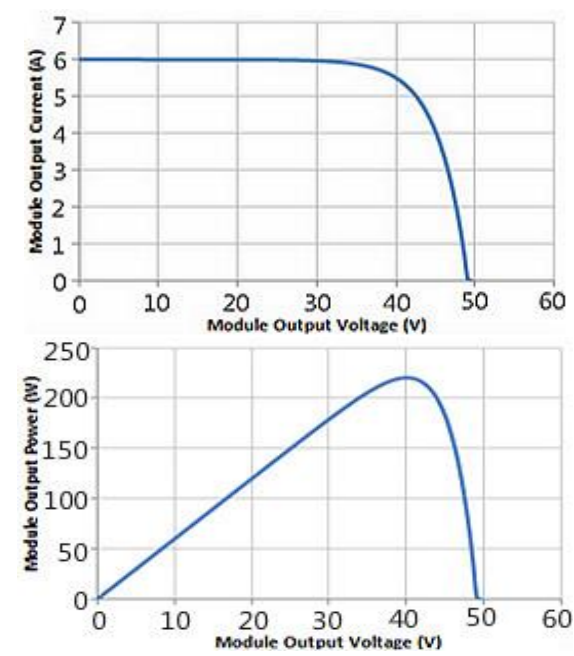

Fig. 2. Typical I-V and P-V characteristics. 
Boost converter, as it name implies, is of a structure that boosts the voltage. Its simplified circuit diagram is shown in Fig. 3. In PV systems, input voltage defined as $V s$ is the voltage in the panel while output voltage, defined as $V o$, is the battery or load voltage. In these circuits, conversion rate is higher than one since output voltage exceeds input voltage [9], [10].

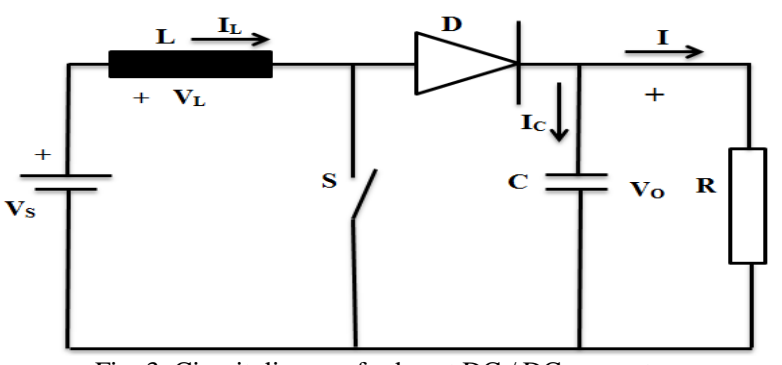

Fig. 3. Circuit diagram for boost DC / DC converter.

MOSFET or IGBT is used as switching element. In eq. $2 d$, which denotes relative conduction time, equals to switching element conduction time $\left(t_{o n}\right)$ divided by signal period which is the total conduction and cut-of time $\left(t=t_{\text {on }}+t_{\text {off }}\right)$.

$$
d=\frac{t_{\text {on }}}{t_{\text {on }}+t_{\text {off }}}=\frac{t_{\text {on }}}{T}
$$

\section{MAXimum Power POINT TRACKING (MPPT)}

The relationship between current and voltage of power that can be obtained from a solar cell is shown in Fig. 4. Each operating point has a unique MPP. To obtain maximum efficiency solar panel should be operated at that point.

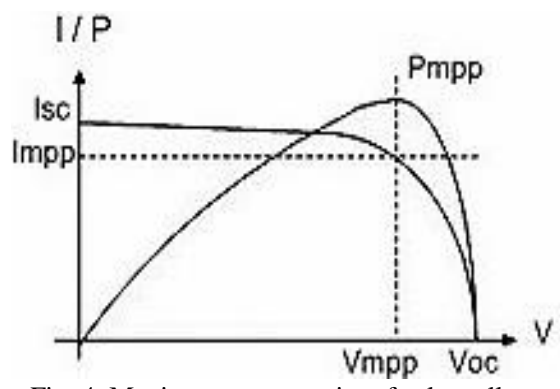

Fig. 4. Maximum power point of solar cell.

Maximum power formula (eq. 3) is given on $I-V$ graph:

$$
\text { Pmpp }=\text { Impp.Vmpp }
$$

\section{Perturbation AND ObSERVE Algorithm}

\section{A. Improving $P \& O$ Algorithm}

$\mathrm{P} \& \mathrm{O}$ algorithm is most commonly used approach in practice due to its applicability. It enables to make a decision through analyzing the change in output power following a tentative voltage increase and decrease in PV system. This algorithm is also called hill climbing. $\mathrm{P}-\mathrm{V}$ curve in $\mathrm{PV}$ panel is used in this algorithm. The amount of change $(\Delta P)$ in PV panel is measured following a deliberate slight increase. If $\Delta P$ value is positive, operating voltage is increased again, which causes PV panel operating point to reach its MPP. In other words, output voltage is monitored constantly and it is determined whether to decrease or increase reference after a correlation between control variable and power movements is established. This algorithm and changing values are given in Table I.

TABLE I: SUMMARY OF P\&O ALGORITHM [11]

\begin{tabular}{ccc}
\hline \hline Perturb. & Change in Power & Next Perturbation \\
\hline \hline Positive & Positive & Positive \\
Positive & Negative & Negative \\
Negative & Positive & Negative \\
Negative & Negative & Positive \\
\hline \hline
\end{tabular}

As seen above, this method includes maximum power tracking through oscillation around MPP. It is preferred due to its simple structure. P\&O algorithm is a useful MPPT algorithm as far as PV energy conversion where changes in sunlight radiation are constant or slowly atmospheric conditions [12], [13]. This problem can be solved to decrease the perturbation step; but, the tracking response will be slower. In rapidly changing weather conditions, $\mathrm{P} \& \mathrm{O}$ algorithm can occasionally make the system operating point far from the MPP. Flowchart of the method is given in Fig. 4.

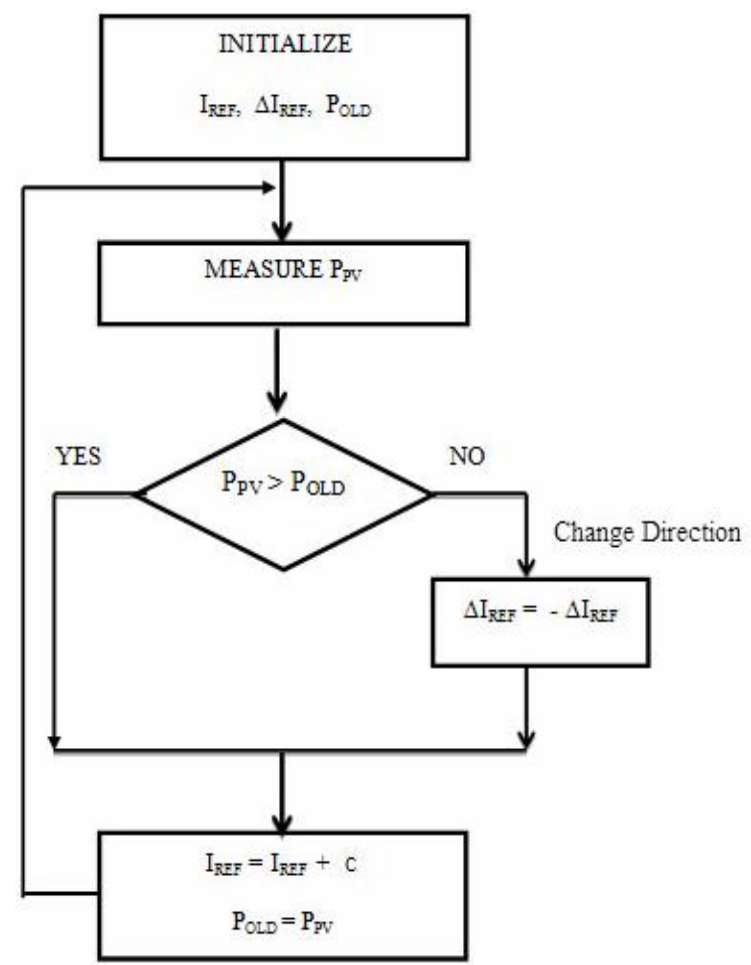

Fig. 4. Basic flowchart implementing the typical $\mathrm{P} \& \mathrm{O}$ algorithm.

Power reference current measured in this method is increased by a constant $c$ which reference $\Delta I$ current increment and we used $c$ coefficient to determine whether the power changes or not through. It is based on the principle that an increase in the power increases current in the same direction while a decrease leads to a direction change, thus causing a decrease in reference current. Adding or subtracting constant coefficients leads to oscillation around maximum power point (eq. 4). 


$$
\text { Iref }=\text { Iref }+c
$$

These oscillation problems may be reducing by improving $\mathrm{P} \& \mathrm{O}$ algorithm. In the following sentence, the algorithm with modification will be presented.

In the proposed algorithm, instead of constant $\Delta I$ coefficient used to increase or decrease reference current, $\Delta I$ (eq. 5), denoting amount of power change, is used in order to approach maximum power point in proportion to an increase or decrease. In other words, a parallel coefficient was provided for power change to faster identify maximum power point. In case of no current change, no iteration was performed and oscillation was minimized (eq. 6).

$$
\begin{aligned}
& \Delta I=\text { Ipv }- \text { Iold } \\
& \text { Iref }=\text { Iref }+\Delta I
\end{aligned}
$$

\section{B. Comparison Conventional and Proposed $P \& O$ Algorithm}

In simulation, case is considered to compare with both algorithms. In case, outputs of PV panels are considered when radiation increases.

Results obtained from the modeling in MATLAB are presented in this section. Solar irradiation is $980 \mathrm{~W} / \mathrm{m}^{2}$ at starting point. Irradiation is increased to $996 \mathrm{~W} / \mathrm{m}^{2}$ linearly until 16th seconds (see Fig. 5).

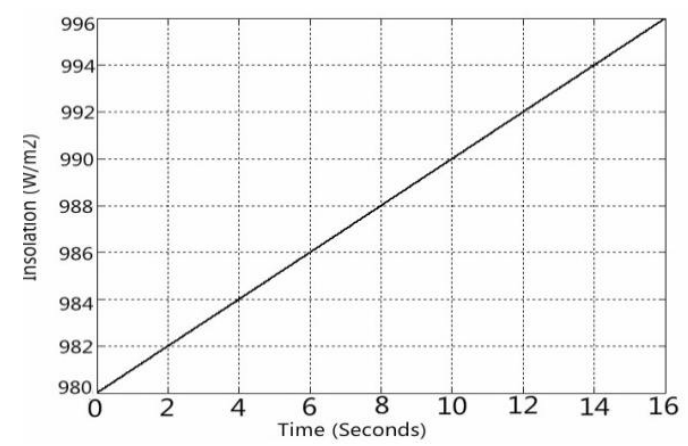

Fig. 5. Solar radiation change.

In this case, a linear increase was observed in the system which is exposed to a radiation rate of $980 \mathrm{~W} / \mathrm{m}^{2}$ for 16 seconds and the radiation increased to $996 \mathrm{~W} / \mathrm{m}^{2}$. In view of this change, this can be considered as slow, classical method and response of identical systems operated by modified method were compared. Current response is compared in Fig. 6.
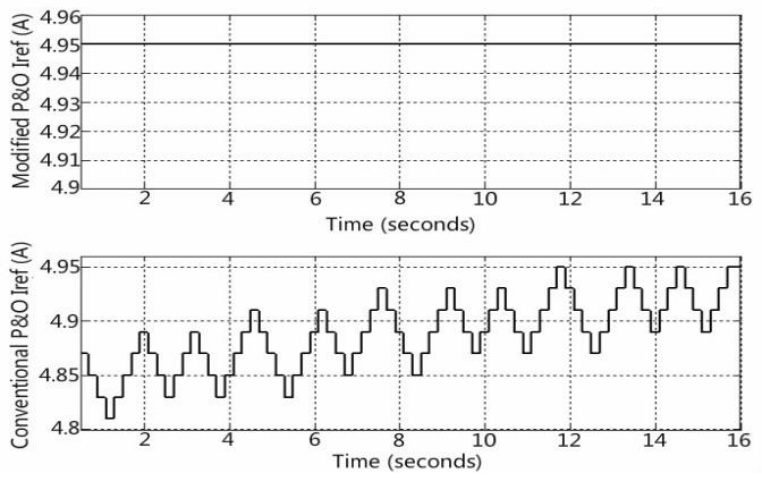

Fig. 6. Reference current in (a) proposed (b) conventional algorithms.
As these result also suggest, oscillation persist in conventional method. These oscillations pose disadvantage because they affect total efficiency of the panel and extend MPPT identification time.

\section{MPPT MATLAB / SIMULINK SIMULATION}

The different initial radiation values were examined for two different operating points in the simulations. First, the sample evaluation for constant reference current was performed without using MPPT. Then the comparison between output power and efficiency has been done with the same case study using MPPT unit. All simulations used in the Simulink model can be seen in Fig. 7. Parameters of the PV panel which was composed for the simulation were given Table II.

\begin{tabular}{cc} 
TABLE II: PARAMETERS OF PV PANEL OF SIMULINK MODEL \\
\hline Short-circuit current & $\mathbf{5 . 4 5 ~ A}$ \\
Open-circuit voltage & $\mathbf{2 2 . 2 ~ V}$ \\
Current at Pmax & $4.95 \mathrm{~A}$ \\
Voltage at Pmax & $\mathbf{1 7 . 2 ~ V}$ \\
\hline \hline
\end{tabular}

\section{A. Operating of the System without MPPT}

It is possible to use same model by switching element on-off according to the cases with MPPT and without MPPT. In initial operation without MPPT starts with an illumination value of $1000 \mathrm{~W} / \mathrm{m}^{2}$ and then increased $1050 \mathrm{~W} / \mathrm{m}^{2}$ in 50 seconds.

The output graphs of the simulation without MPPT are given Fig. 8.
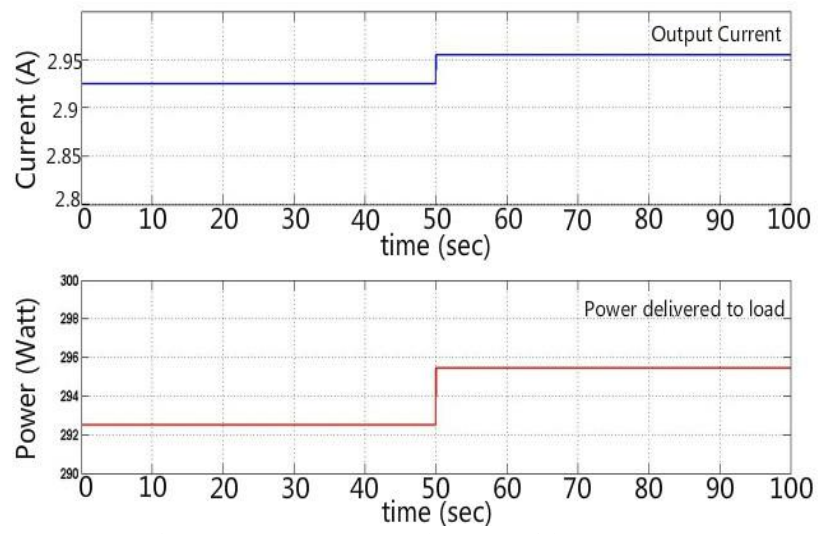

Fig. 8. Output current and power without MPPT.

\section{B. Operating of System with MPPT}

In the same case study, output powers and currents analyzed according to current reference that can be changed by illumination level with MPPT. In this part, a simulation which is shown in Fig. 7 is used. The blocks in Fig. 9 are used with MPPT controller. $\mathrm{P} \& \mathrm{O}$ algorithm is written as code file with $m$ extension.

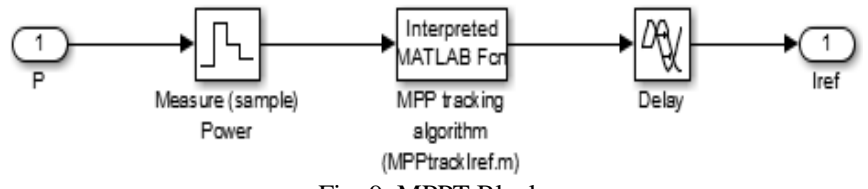

Fig. 9. MPPT Block. 


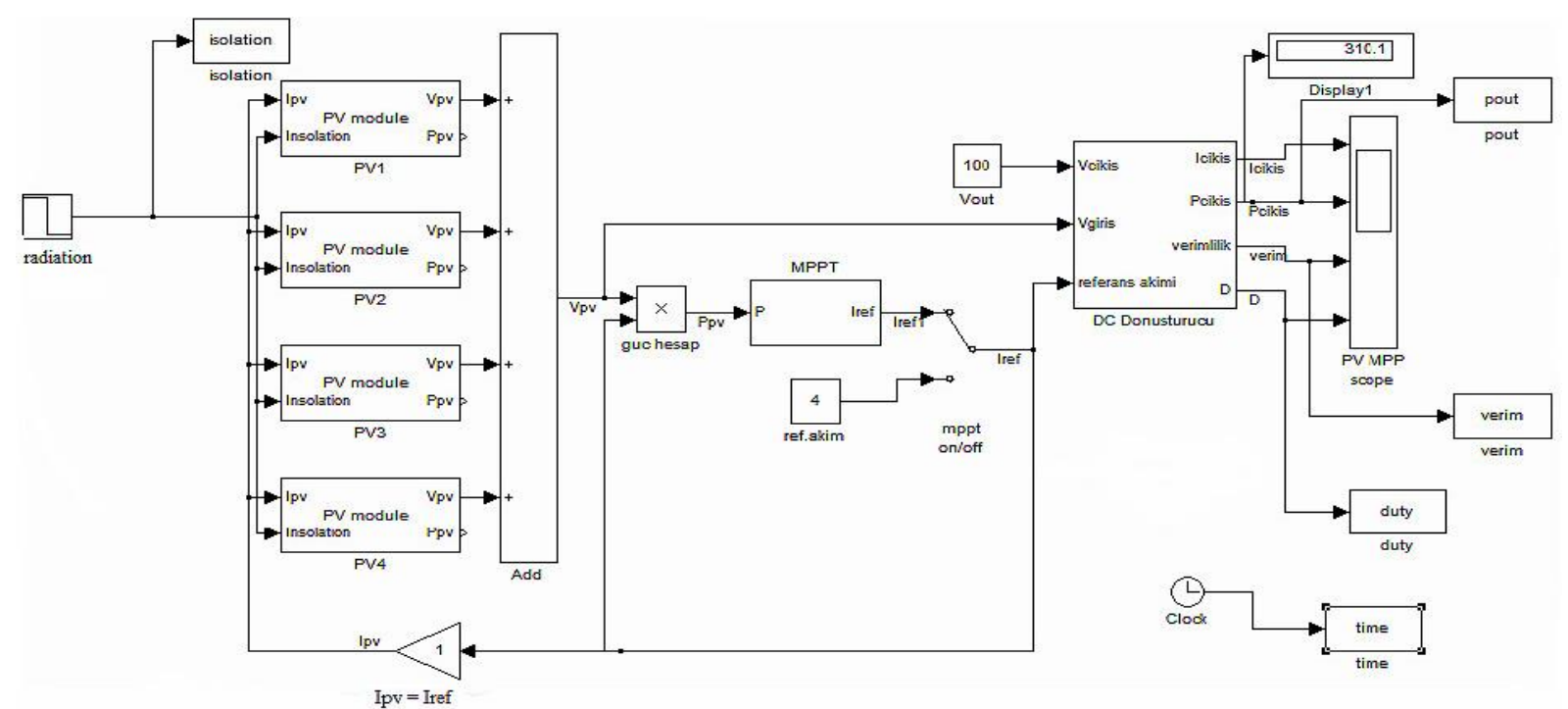

Fig. 7. MATLAB model for simulation.
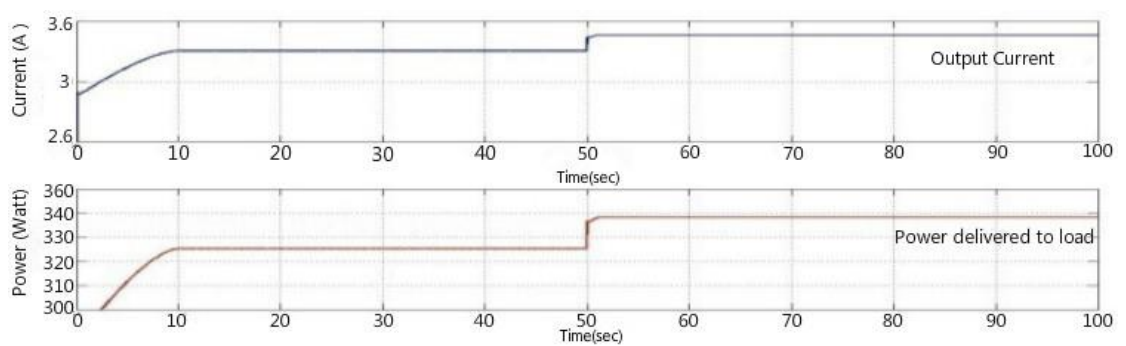

Fig. 10. Output current and power with MPPT.

The output graphs of the simulation with MPPT are given Fig. 10 .

\section{Comparison MATLAB/Simulink Results}

Fig. 8 with Fig. 10 must compare. When illumination level increase, the increasing of output powers is observed in cases with and without MPPT.

The comparisons of output powers provide better understanding. Initially in $1000 \mathrm{~W} / \mathrm{m}^{2}$ illumination value, load absorbed 325.3 W with MPPT and 292.5 W without MPPT. In 50 seconds when illumination value increased by $50 \mathrm{~W} / \mathrm{m}^{2}$ load absorbs $338.2 \mathrm{~W}$ with MPPT, $295.5 \mathrm{~W}$ without MPPT. To understand the difference better, output powers at different illumination values is analyzed and results are tabulated in Table III.

TABLE III: OUTPUT POWERS AT DIFFERENT ILLUMINATION VALUES

\begin{tabular}{|c|c|c|c|c|c|}
\hline W/m & $\begin{array}{c}\text { Pout } \\
\text { MPPT' siz }\end{array}$ & $\begin{array}{c}\Delta \text { Pout } \\
\text { MPPT' siz }\end{array}$ & $\begin{array}{c}\text { Pout } \\
\text { MPPT' li }\end{array}$ & $\begin{array}{c}\Delta \text { Pout } \\
\text { MPPT' li }^{\prime}\end{array}$ & $\Delta$ \\
\hline 1000 & 292.5 & & 325.3 & & $\mathbf{3 2 . 8}$ \\
\hline & & 3 & & 12.9 & \\
\hline 1050 & 295.5 & & 338.2 & & $\mathbf{4 2 . 7}$ \\
\hline
\end{tabular}

As shown in Fig. 3, at illumination value of $1000 \mathrm{~W} / \mathrm{m}^{2}$, the difference between obtained power with using and without using MPPT is $32.8 \mathrm{~W}$. After increasing illumination value by $50 \mathrm{~W} / \mathrm{m}^{2}$, the difference between obtained power with using and without using MPPT is $42.7 \mathrm{~W}$ using MPPT increases the efficiency as illumination value increases.

\section{THE STUDY OF MPPT UNIT IN WIRELESS TRANSMISSION IN EXPERIMENTAL PHOTOVOLTAIC SYSTEM}

In experimental set up parallel connected two solar panel
SM $260 \mathrm{~s}$ is used as shown in Fig. 11.

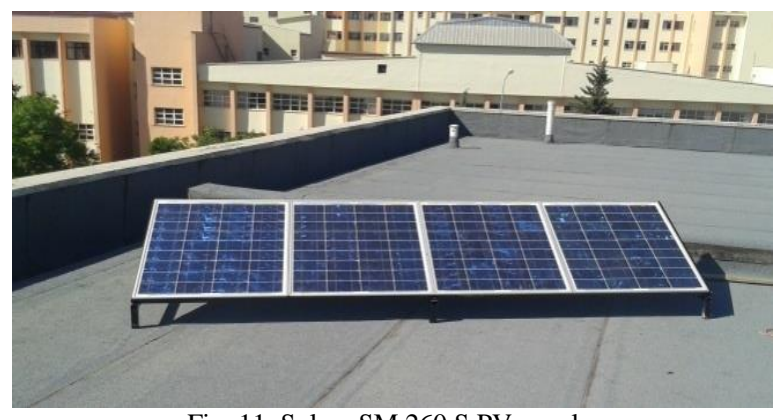

Fig. 11. Solara SM 260 S PV panels.

Parameters of Solara SM 260 S PV panel which was used in experimental setup were given Table IV.

TABLE IV: PARAMETERS OF SOLARA SM 260 S PV PANEL

\begin{tabular}{cc}
\hline \hline Short-circuit current & $4.2 \mathrm{~A}$ \\
Open-circuit voltage & $21.6 \mathrm{~V}$ \\
Current at Pmax & $3.74 \mathrm{~A}$ \\
Voltage at Pmax & $17.24 \mathrm{~V}$ \\
\hline
\end{tabular}

In wireless transmission two systems are used as an application. One is conventional and the other is PV system with MPPT. In both systems 12 V, 10 A DC/DC converters are used. Wireless energy transmitting device is shown in Fig. 12. Helical coils which are used in wireless power capture and wireless power transmitter have same property Diameter of helical coils and wire are $250 \mathrm{~mm}$ and $0,7 \mathrm{~mm}$ respectively. By producing two opposite magnetic flux in mutual inductance of transmitting circuit ac voltage is obtained. 


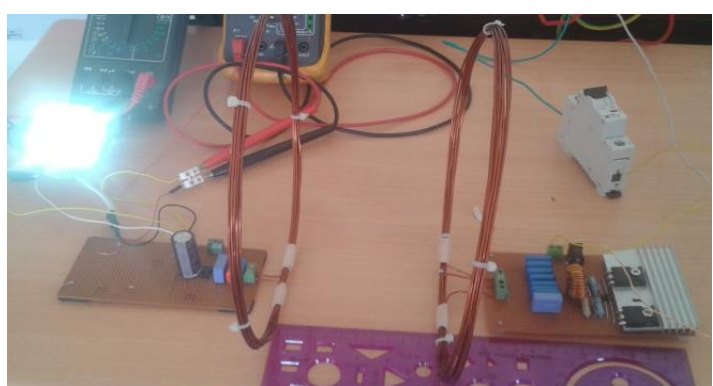

Fig. 12. Wireless energy transmitting device.

IRFP $250 \mathrm{~N}$ mosfets which used for DC / AC conversion are operated $25 \mathrm{Khz}$ switching frequency (Fig. 13).

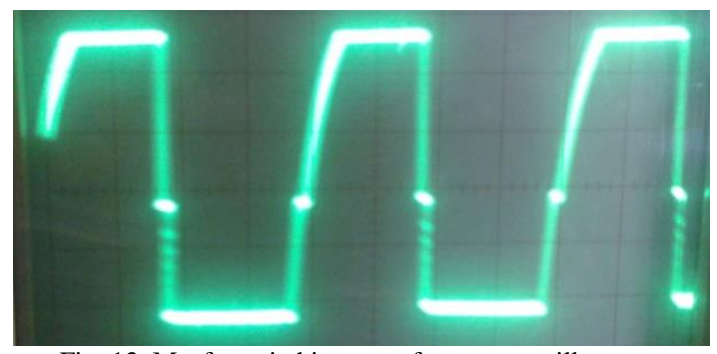

Fig. 13. Mosfet switching waveforms on oscilloscope. $(\mathrm{Ch} 1=5 \mathrm{~V}$, time $=10 \mu \mathrm{s})$

DC voltage is gotten from PV panel which entered to wireless transmission device is showed Fig. 14.

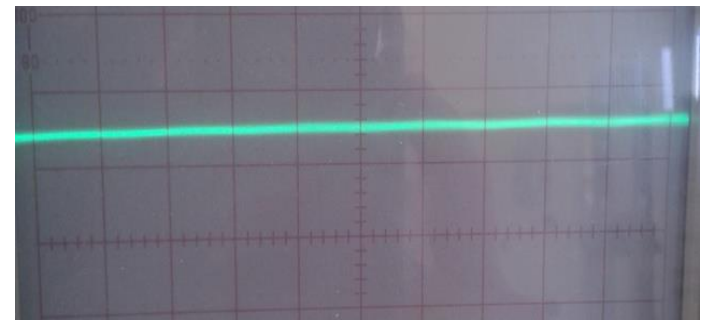

Fig. 14. Waveforms of input DC voltage in wireless energy transmission.

Output voltage that is composed to wireless energy transmitting device is shown in Fig. 15.

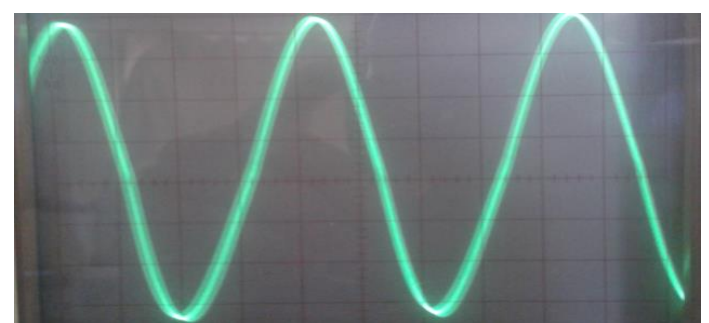

Fig. 15. Waveforms of output voltage in wireless energy transmission. device $(\mathrm{Ch} 1=5 \mathrm{~V}$, time $=10 \mu \mathrm{s})$.

Input voltage that is transferred to wireless energy transfer capture circuit is shown in Fig. 16.

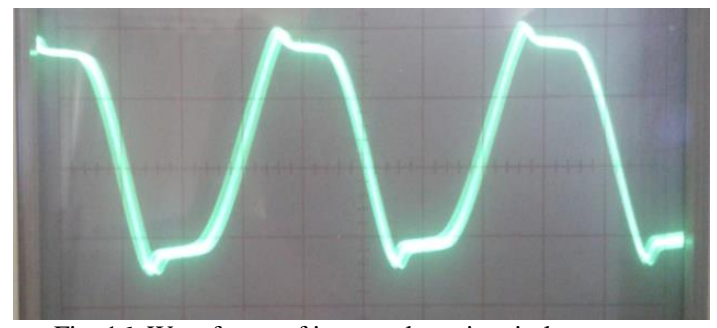

Fig. 16. Waveforms of input voltage in wireless power. capture device $(\mathrm{Ch} 1=5 \mathrm{~V}$, time $=10 \mu \mathrm{s})$.
Output voltage of wireless power capture device is shown in Fig. 17.

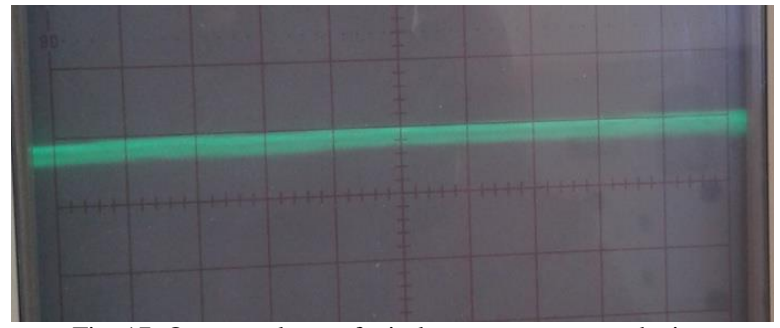

Fig. 17. Output voltage of wireless power capture device.

\section{A. Conventional PV Wireless Energy Transmission}

Block structure of conventional PV Wireless Energy Transmission is shown Fig. 18.
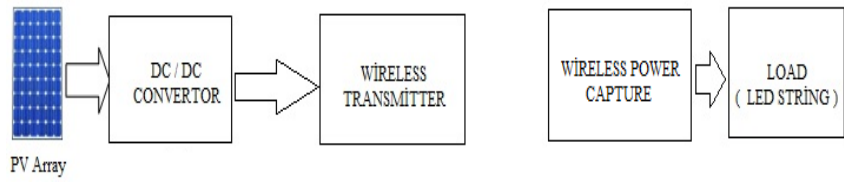

Fig. 18. Conventional PV wireless energy transmission.

Input/output voltages and currents are obtained by using pwm switching in buck-boost DC/DC convertor with a distance of 1 to $5 \mathrm{~cm}$ between wireless power transmitter and wireless power capture. Power and efficiency values are shown in Table $\mathrm{V}$ and efficiency is calculated [14], [15] by using (eq. 7) with operating temperature of $33{ }^{\circ} \mathrm{C}$ and illumination value of $937 \mathrm{~W} / \mathrm{m}^{2}$.

$$
\eta=\frac{P_{0}}{P_{i}} \times 100 \%=\left(\frac{V_{0}^{2}}{R_{0}}\right) /\left(\frac{V_{S}-V_{i}}{R_{S}}\right) \times V_{i}
$$

where $\eta=$ Transmitting efficacy, $V_{s}=$ Transmitting terminal voltage, $V_{i}=$ Input voltage, $V_{o}=$ Output voltage, $P_{i}=$ Input voltage, $P_{o}=$ Output power, $R_{S}=$ System internal resistance, $R_{o}=$ Load resistance

TABLE V: The VALues ARE GotTen CONVENTIONAL PV WiRELESS ENERGY TRANSMISSION

\begin{tabular}{cccccccc}
\hline \hline Distance & $\boldsymbol{V}_{\boldsymbol{i}}$ & $\boldsymbol{I}_{\boldsymbol{i}}$ & $\boldsymbol{P}_{\boldsymbol{i}}$ & $\boldsymbol{V}_{\boldsymbol{o}}$ & $\boldsymbol{I}_{\boldsymbol{o}}$ & $\boldsymbol{P}_{\boldsymbol{o}}$ & $\boldsymbol{\eta}(\boldsymbol{\%})$ \\
\hline \hline $1 \mathrm{~cm}$ & 10.55 & 1.28 & 13.5 & 18.23 & 0.34 & 6.19 & 45.85 \\
$2 \mathrm{~cm}$ & 10.80 & 1.08 & 11.66 & 17.12 & 0.29 & 4.96 & 42.53 \\
$3 \mathrm{~cm}$ & 11.24 & 0.90 & 10.11 & 15.70 & 0.23 & 3.61 & 35.70 \\
$4 \mathrm{~cm}$ & 11.68 & 0.72 & 8.4 & 14.0 & 0.17 & 2.38 & 28.33 \\
$5 \mathrm{~cm}$ & 12.10 & 0.58 & 7.01 & 12.20 & 0.10 & 1.22 & 17.40 \\
\hline \hline
\end{tabular}

\section{B. Solar Wireless Energy Transmission Systems Using MPPT}

Block structure of Solar Wireless Energy Transmission Systems using MPPT is shown in Fig. 19.
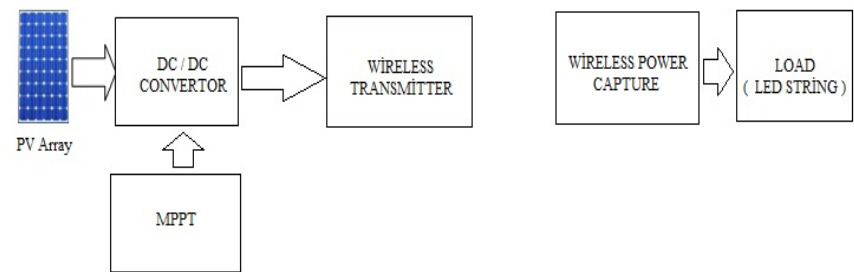

Fig. 19. Solar wireless energy transmission systems using MPPT. 
Input/Output voltages, currents, powers and efficiency values are shown in Table VI which is obtained by using pwm switching which uses $\mathrm{P} \& \mathrm{O}$ algorithm by controlling buck-boost DC/DC convertor with a distance of 1 to $5 \mathrm{~cm}$ between wireless power transmitter and wireless power capture.

TABLE VI: The VALUeS ARE GOTTEN SOLAR WIRELESS ENERGY TRANSMISSION SYSTEMS USING MPPT

\begin{tabular}{cccccccc}
\hline \hline Distance & $\boldsymbol{V}_{\boldsymbol{i}}$ & $\boldsymbol{I}_{\boldsymbol{i}}$ & $\boldsymbol{P}_{\boldsymbol{i}}$ & $\boldsymbol{V}_{\boldsymbol{o}}$ & $\boldsymbol{I}_{\boldsymbol{o}}$ & $\boldsymbol{P}_{\mathbf{o}}$ & $\boldsymbol{\eta}(\boldsymbol{\%})$ \\
\hline \hline $1 \mathrm{~cm}$ & 10.52 & 1.40 & 14.72 & 19.12 & 0.37 & 7.07 & 48 \\
$2 \mathrm{~cm}$ & 11.05 & 1.17 & 12.92 & 17.82 & 0.32 & 5.7 & 44.1 \\
$3 \mathrm{~cm}$ & 11.60 & 0.91 & 10.55 & 15.91 & 0.24 & 3.81 & 36.11 \\
$4 \mathrm{~cm}$ & 11.95 & 0.74 & 8.84 & 14.22 & 0.17 & 2.41 & 27.26 \\
$5 \mathrm{~cm}$ & 12.23 & 0.61 & 7.46 & 12.65 & 0.12 & 1.51 & 20.24 \\
\hline \hline
\end{tabular}

\section{Comparison of Conventional and Using MPPT PV Wireless Energy Transmission}

Experiment carried out by using two $65 \mathrm{~W}$ parallel connected PV panel with operating temperature of $33^{\circ} \mathrm{C}$ and illumination value of $937 \mathrm{~W} / \mathrm{m}^{2}$ shows that efficiency of wireless power transmission is inversely proportional with distance. Solar wireless energy transmission systems using MPPT is more efficient than conventional systems.

\section{CONCLUSION}

In this study simulation of PV generators that are capable of producing different output powers are used. In this simulation output power is measured and DC/DC converter is controlled by using MPPT and without using MPPT. In PV energy conversion systems using MPPT increases output power and efficiency. This results in usage of fewer amounts of panel and reduced cost.

In rapidly changing weather conditions $\mathrm{P} \& \mathrm{O}$ algorithm can occasionally make the system operating point far from MPP. The oscillation is shown in Fig. 6, 10. In simulation linearly changed illumination value is used thus less oscillation is observed then real experiment.

This study focuses on improving algorithm and eliminating oscillation problems in P\&O MPPT algorithm. Particularly, when variability increases as a result of factors such as partial shadowing and cloudy weather, these oscillations are bound to affect the system more. Therefore, it is suggested that this improvement attempts for the algorithm will yield positive results in terms of system efficiency. It is also possible to suggest that changes in the algorithm will pose no difficulties in terms of hardware, which makes it suitable for experimental purposes. In the upcoming studies, it is required to improve the algorithm as far as hardware is concerned.

By the spread of electric vehicles and portable electronic devices, battery charging problem is further increased the importance of the wireless energy transmission. In this study, the most important renewable energy sources, solar energy, is integrated with wireless energy transmission by using conventional system and system using MPPT. Both systems are compared experimentally and this comparison results in systems using MPPT are more efficient than the conventional systems.
For further studies both temperature and illumination value can be changed separately or simultaneously.

\section{REFERENCES}

[1] M. A. Ozcelik and A. S. Yilmaz, "Improving the efficiency of PV system under different insolation levels," in Proc. National Symposium of Electric, Electronics and Computer Engineering, 2012, pp. 1-2.

[2] S. Panwar et al., "Development and simulation of solar photovoltaic model using Matlab/simulink and its parameter extraction," in Proc. Int. Conf. on Computing and Control Engineering, 2012, pp. 2-5.

[3] J. A. R. Hernanz et al., "Two photovoltaic cell simulation models in Matlab/Simulink," International Journal on Technical and Physical Problems of Engineering, pp. 45-47, 2012.

[4] M. Sree and R. Ramaprabha, "Design and modeling of standalone solar photovoltaic charging system," International Journal of Computer Applications, vol. 18, no. 2, 2011.

[5] N. Pandiarajan and R. Ramabadran, "Application of circuit model for Photovoltaic Energy Conversion System," International Journal of Photo Energy, pp. 4-5, 2012.

[6] G. Bayrak and M. Cebeci, "Modelling $3.6 \mathrm{~kW}$ installed power PV generator with Matlab simulink," Journal of the Institute of Science and Technology, vol. 28, issue 2, pp. 198-203, 2011.

[7] S. Rustemli and F. Dincer, "Modeling of photovoltaic panel and examining effects of temperature in Matlab/simulink," Journal of Electronics and Electrical Engineering, vol. 3, no. 109, pp. 35-40, March 2011.

[8] S. M. Zahra, M. Saad, and S. M. Mohsen, "MPPT with Inc. Cond method using conventional interleaved boost converter," Energy Proceeding, vol. 42, pp. 24-32, 2013.

[9] S. Azadeh and M. Saad, "Simulation and hardware implementation of incremental conductance MPPT with direct control method using CUK converter," IEEE Transactions on Industrial Electronics, vol. 58, no. 4, April 2001.

[10] C. Kai, T. Shulin, and C. Yuhua, "An improved MPPT controller for photovoltaic system under partial shading condition," IEEE Transactions on Sustainable Energy, vol. 5, no. 3, pp. 978-985, 2014.

[11] V. Salas et al., "Evaluation of a new maximum power point tracker (MPPT) applied to the photovoltaic standalone systems," Solar Energy Materials and Solar Cells, vol. 87, pp. 807-815, 2005.

[12] T. Esram and P. L. Chapman, "Comparison of photovoltaic array maximum power point tracking techniques," IEEE Trans on Energy Conversion, vol. 22, no. 2, pp. 439-449, 2007.

[13] M. G. Wanzeller et al., "Current control loop for tracking of maximum power point supplied for photovoltaic array," IEEE Trans on Instrumentation and Measurement, vol. 53, pp. 1304-1310, 2004.

[14] G. Like, H. S. Wen, X. W. Xiong, J. D. Qi, W. D. Zhi, Z. Hong, and J. Yan, "Optimum design of coil for wireless energy transmission system based on resonant coupling," in Proc. IEEE International Conference on Control and Automation, June 12-14, 2013, pp. 190-195.

[15] S. Peter and B. Philip, "Wireless energy transmission system for low-power devices," in Proc. IEEE Sensors Conference, 2008, pp. 33-36.

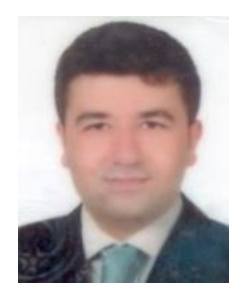

Mehmet Ali Özçelik was born in İskenderun, Turkey He received his B.E. and M.E. degrees in electrica education from Marmara University, Istanbul and in electrical \& electronics engineering from Sutcu Imam University, Kahramanmaras, Turkey, in 1999, 2006, respectively. $\mathrm{He}$ is an instructor in Gaziantep University. He is currently $\mathrm{PhD}$ student in Sutcu Imam University. His field of interest includes PV energy conversion systems and MPPT algorithms.

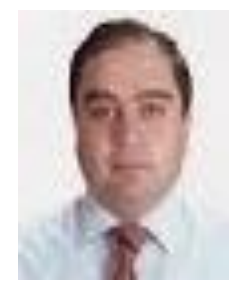

Ahmet Serdar Yılmaz was born in kahramanmaras, Turkey. He received the B.E., M.E., and PhD Eng. degrees in electrical \& electronics engineering from Sakarya University, Turkey, in 1994, 1997 and 2002 respectively. In 1995 he joined the Department of Electrical and Electronics Engineering, Sakarya University, as a research assistant then became an assistant professor and an associate professor in 2003 and 2011, respectively. He is a currently an associate professor at the Department of Electrical and Electronics Engineering, Sutcu İmam University, Kahramanmaras, Turkey. His current research interests include power quality, power systems, wind and solar energy conversion systems. He is a member of the IEEE. 